\title{
RESEARCH
}

Open Access

\section{Morbidity and mortality due to malaria in Est Mono district, Togo, from 2005 to 2010: a times series analysis}

Essoya D Landoh ${ }^{1,2^{*}}$, Potougnima Tchamdja ${ }^{3}$, Bayaki Saka ${ }^{3}$, Khin S Tint ${ }^{2,4}$, Sheba N Gitta ${ }^{5}$, Peter Wasswa ${ }^{5}$ and Christiaan de Jager ${ }^{2}$

\begin{abstract}
Background: In 2004, Togo adopted a regional strategy for malaria control that made use of insecticide-treated nets (ITNs), followed by the use of rapid diagnostic tests (RDTs), artemisinin-based combination therapy (ACT). Community health workers (CHWs) became involved in 2007. In 2010, the impact of the implementation of these new malaria control strategies had not yet been evaluated. This study sought to assess the trends of malaria incidence and mortality due to malaria in Est Mono district from 2005 to 2010.

Methods: Secondary data on confirmed and suspected malaria cases reported by health facilities from 2005 to 2010 were obtained from the district health information system. Rainfall and temperature data were provided by the national Department of Meteorology. Chi square test or independent student's t-test were used to compare trends of variables at a 95\% confidence interval. An interrupted time series analysis was performed to assess the effect of meteorological factors and the use of ACT and CHWs on morbidity and mortality due to malaria.

Results: From January 2005 to December 2010, 114,654 malaria cases (annual mean 19,109 $\pm 6,622$ ) were reported with an increase of all malaria cases from 10,299 in 2005 to 26,678 cases in 2010 ( $p<0.001$ ). Of the 114,654 malaria cases 52,539 (45.8\%) were confirmed cases. The prevalence of confirmed malaria cases increased from 23.1 per 1,000 in 2005 to 257.5 per 1,000 population in 2010 ( $p<0.001$ ). The mortality rate decreased from 7.2 per 10,000 in 2005 to 3.6 per 10,000 in 2010 ( $p<0.001$ ), with a significant reduction of $43.9 \%$ of annual number of death due to malaria. Rainfall ( $\beta$-coefficient $=1.6 ; p=0.05$ ) and number of $\mathrm{CHWs}$ trained ( $\beta$-coefficient $=6.8 ; \mathrm{p}=0.002$ ) were found to be positively correlated with malaria prevalence.

Conclusion: This study showed an increase of malaria prevalence despite the implementation of the use of ACT and CHW strategies. Multicentre data analysis over longer periods should be carried out in similar settings to assess the impact of malaria control strategies on the burden of the disease. Integrated malaria vector control management should be implemented in Togo to reduce malaria transmission.
\end{abstract}

Keywords: Malaria, Mortality, Morbidity, ACT, Rainfall, Time series analysis, Togo

\footnotetext{
* Correspondence: mlandoh@yahoo.fr

1Division de l'Epidémiologie, Ministère de la Santé du Togo, BP: 1396, Lomé,

Togo

${ }^{2}$ UP Centre for Sustainable Malaria Control, School of Health Systems \&

Public Health, University of Pretoria, Pretoria, South Africa

Full list of author information is available at the end of the article
} 


\section{Background}

Malaria remains a major public health concern. According to the World Malaria Report 2010, the global prevalence of the disease was estimated at 225 million cases and 781,000 deaths in 2009 [1]. About 80\% of these cases occur in sub-Saharan Africa, with rural areas that have poor access to health services being most affected $[2,3]$. In Togo, malaria is a priority disease because of the high morbidity and mortality associated with it. The disease accounted for 39\% of out-patient consultations, $21 \%$ of hospital admissions and $4.9 \%$ of case fatalities in 2007 [4].

Malaria control strategies primarily comprise prevention through vector control, such as indoor residual spraying (IRS) or the use of personal preventive methods such as bed nets and mosquito repellents followed by chemoprophylaxis. Control also takes the form of effective case management and medication. The implementation of these strategies has been supported by donor funding and the commitment of governments and partners from many countries [5]. In many developing countries there is variable success in vector control using insecticide-treated bed nets (ITNs) and IRS with dichlorodiphenyltrichloroethane (DDT) or other agents [6,7].

Since 2004, the Togolese government has adopted a regional strategy of malaria control through the use of ITNs, the use of artemisinin-based combination therapy (ACT) as well as community involvement [4]. Malaria control strategies in Est Mono district include promotion of the use of ITNs in the community, which is one of the main technical approaches of the Roll Back Malaria campaign (RBM), implemented in late 2004 in Togo. In 2007, the country started the implementation of artemether-lumefantrine as firstline treatment for uncomplicated malaria in all public health facilities and by community health workers (CHWs) because rapid diagnostic tests (RDTs) to confirm malaria could be carried out even in health facilities that did not have the laboratory capacity. CHWs were trained to promote health, treat uncomplicated malaria cases within their communities and report data to their respective health care centres. These strategies aimed at increasing the accessibility of health care to isolated populations and those populations living beyond five kilometres of health facilities and to reduce morbidity and mortality due to malaria by $50 \%$ in 2012 from 2005 levels [4].

After five years, the impact of the implementation of the new malaria control strategies on the malaria burden in Est Mono district remained unknown. The objective of this study was to assess the trends of malaria prevalence and specific mortality due to malaria in Est Mono district from 2005 to 2010.

\section{Methods}

\section{Design of the study}

The study took the form of a retrospective secondary data analysis of malaria trends from 2005 to 2010. The district collects health information routinely from health facilities and compiles the data on a monthly basis. The completeness of data in the district was $97 \%$ during the study period [8].

\section{Setting}

Est Mono district covers an area of $2,474 \mathrm{~km}^{2}$ with a population of 89,060 inhabitants and a population growth rate of $1.03 \%$ in 2010 [8]. Est Mono is one of the nine health districts in the Plateaux region, which is one of Togo's six regions. The district is situated in central Togo and has 17 health facilities run by nurses, auxiliary nurses, or nonqualified nurses. Each health unit has CHWs trained in health promotion and the management of uncomplicated malaria cases within their communities.

Est Mono district [8] and the other central and southern parts of Togo have two rainy seasons, the first starting in April and ending in July and the second starting in September and ending in late November. The district receives on average $949 \mathrm{~mm}( \pm 37.4)$ of precipitation annually or $79 \mathrm{~mm}( \pm 3.1)$ each month. The climate in Togo is generally tropical, with average temperatures ranging from $27.5^{\circ} \mathrm{C}\left(81.5^{\circ} \mathrm{F}\right)$ on the coast to about $30^{\circ} \mathrm{C}$ $\left(86^{\circ} \mathrm{F}\right)$ in the north. Malaria transmission is seasonal, with peaks related to rainfall.

\section{Data collection}

Secondary aggregated data on confirmed and suspected malaria cases reported by health facilities from 2005 to 2010 were obtained from the Malaria Control Programme of the district health information system. The population estimates were obtained from the district to calculate prevalence and specific mortality rate due to malaria [8]. Information on the number of $\mathrm{CHWs}$ trained each year was gained from the district register. Data on ACT were abstracted from the monthly health facility reports sent to the district. Rainfall and temperature data from 2005 to 2010 were provided by the Department of Meteorology in Togo.

\section{Data analysis}

Suspected malaria cases were defined as any person presenting with fever $\left(>38^{\circ} \mathrm{C}\right)$ for less than two days or having a history of fever associated with symptoms such as nausea, vomiting and diarrhoea, headache, back pain, chills, myalgia, where other infectious diseases have been excluded and a treatment using anti-malarial drugs was successful. Confirmed cases were persons with suspected malaria who had been shown to have malaria parasites by using a parasitological test such as microscopy (using a 
blood smear) or RDT. RDT was used in the health facilities where there was no laboratory and also by CHWs, according to the national malaria control guidelines [4].

Individual-level data were not available and consequently data on age or sex distribution were not provided. However, aggregated data on targeted groups (under five years old, more than five years old and pregnant women) were available. Malaria prevalence and specific mortality rates were calculated using the midyear population, which was estimated from population data based on the 1980 census and assuming a $1.03 \%$ annual population growth each year. The prevalence of malaria per 1,000 people was calculated per year.

The malaria mortality rate was defined as the number of deaths among persons identified as suspected or confirmed malaria cases divided by the mid-year population of the district, while prevalence was defined as the number of reported malaria cases divided by the mid-year population.

The Chi square test was used to compare trends in malaria prevalence in the district and the mortality rate over the six years at a 95\% confidence interval. The Student $\mathrm{t}$-test was performed to compare the rainfall means and mean temperatures. An interrupted time series analysis was performed to assess the effect of rainfall, temperature $[9,10]$, and the use of ACT and CHWs on the transmission of malaria by fitting the ARIMA model (Autoregressive Integrated Moving Average) to calculate trends using the moving average of monthly suspected and confirmed malaria cases. A segmented or piece-wise regression [11,12] was performed for annual reported malaria cases considering the joint point to be 2007 when ACT and CHW strategies were initiated. Data on the number of malaria cases were only available from 2005 onwards and this limited the possibility to use a sufficiently long time series analysis on an annual basis. Analyses were performed using Stata version 11.0.

\section{Ethical issues}

This study was approved by the Faculty of Health Sciences Ethics Committee at the University of Pretoria,
South Africa (Ref No. 79/2010: 04/06/2010) and the Ministry of Health of Togo (Ref No. 1420/2009/MS/ DGS/DSSP/DEPI).

\section{Results}

\section{Malaria cases reported}

All reported outpatient and reported malaria cases are shown in Table 1. During the study period, the proportion of the population using the health care service in Est Mono district increased from 29\% $(22,852 / 79,000)$ in 2005 to $62 \%(55,603 / 89,060)$ in $2010\left(x^{2}=5742 \mathrm{p}<0.001\right)($ Table 1$)$.

From 2005 to 2010 114,654 malaria cases (mean $19109 \pm$ 6622) were reported in Est Mono district with an overall increase of total malaria cases by $159.03 \%$ from 10,299 cases in 2005 to 26,678 cases in $2010\left(x^{2}=702.8 ; \mathrm{p}<0.001\right)$ (Figure 1). Of the 114,654 malaria cases, 52,539 (45.8\%) were confirmed cases (Table 1).

The annual prevalence of confirmed malaria cases increased steeply from 23.1 per 1,000 population in 2005 to 257.5 per 1,000 in 2010 ( $x^{2}=7000.7$; $\left.p<0.001\right)$, indicating a significant increase over time (Table 1). Furthermore, the proportion of confirmed cases increased from $17.7 \%(1,827 / 10,299)$ in 2005 to $85.9 \%(22,935 / 26,678)$ in 2010. A total of 281 deaths were reported in the district between 2005 and 2009. The mortality rate decreased from 7.2 per 10,000 in 2005 to 3.6 per 10,000 in 2010 $\left(\mathrm{X}^{2}=15.9 ; \mathrm{p}<0.001\right)$, with a significant reduction of $43.9 \%$ in the annual number of death due to malaria between 2005 and 2010 (Figure 1).

From 2005 to 2010, the number of suspected and confirmed malaria cases reported was higher among children under five years (Table 2). The proportion of confirmed malaria cases was $46.6 \% \quad(24,473 / 52,539)$ among the population over five years of age, $45.6 \%$ $(23,979 / 52,539)$ among the population below five years, and $7.8 \%(4,087 / 52,539)$ in pregnant women (Table 3$)$.

\section{Availability of ACT and CHW}

The number of days per year where there was a shortage of ACT in Est Mono district decreased from 160 in 2007

Table 1 Trends in malaria cases reported in Est Mono district from 2005 to 2010

\begin{tabular}{lccccccccc}
\hline Years & $\begin{array}{c}\text { Population } \\
\text { of district }\end{array}$ & $\begin{array}{c}\text { Out patient } \\
\text { all causes }\end{array}$ & $\begin{array}{c}\text { Total } \\
\text { reported } \\
\text { malaria } \\
\text { cases N (\%) }\end{array}$ & $\begin{array}{c}\text { Suspected } \\
\text { cases }\end{array}$ & $\begin{array}{c}\text { Reported malaria cases } \\
\text { confirmed } \\
\text { cases }\end{array}$ & $\begin{array}{c}\text { Prevalence } \\
\text { of malaria } \\
\text { all cases } \\
(\mathbf{1} / \mathbf{1}, \mathbf{0 0 0})\end{array}$ & $\begin{array}{c}\text { Prevalence } \\
\text { confirmed cases } \\
(\mathbf{1} / \mathbf{1}, \mathbf{0 0 0})\end{array}$ & $\begin{array}{c}\text { No. of reported } \\
\text { death due } \\
\text { to malaria }\end{array}$ & $\begin{array}{c}\text { Specific } \\
\text { mortality rate } \\
(\mathbf{1} / \mathbf{1 0 , 0 0 0})\end{array}$ \\
\hline $\mathbf{2 0 0 5}$ & 79,000 & 22,852 & $10,299(45.1)$ & 8,472 & 1,827 & 130.4 & 23.1 & 57 & $\mathbf{7 . 2}$ \\
$\mathbf{2 0 0 6}$ & 81,000 & 25,354 & $12,843(50.7)$ & 11,961 & 882 & 158.6 & 10.9 & 57 & $\mathbf{7 . 0}$ \\
$\mathbf{2 0 0 7}$ & 82,673 & 31,819 & $17,776(55.9)$ & 12,777 & 4,999 & 215.0 & 60.5 & 53 & $\mathbf{6 . 4}$ \\
$\mathbf{2 0 0 8}$ & 84,931 & 39,834 & $22,068(55.4)$ & 12,019 & 10,049 & 259.8 & 118.3 & 58 & $\mathbf{6 . 8}$ \\
$\mathbf{2 0 0 9}$ & 86,980 & 46,876 & $24,990(53.3)$ & 13,143 & 11,847 & 287.3 & 136.2 & 24 & $\mathbf{2 . 8}$ \\
$\mathbf{2 0 1 0}$ & 89,060 & 55,603 & $26,678(48.0)$ & 3,743 & 22,935 & 299.6 & 257.5 & 32 & $\mathbf{3 . 6}$ \\
\hline
\end{tabular}




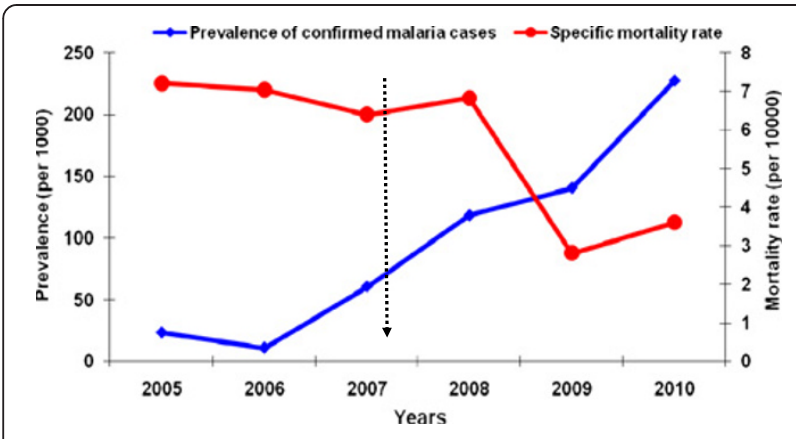

Figure 1 Change in malaria prevalence and mortality from 2005 to 2010 in Est Mono district before and after implementation of ACT and CHW involvement strategies.

to 23 in 2010. A total of $220 \mathrm{CHWs}$ were trained in 2007 compared to $310 \mathrm{CHWs}$ trained annually between 2008 and 2010 (Table 4).

\section{Seasonality of malaria}

The level of annual rainfall was similar from 2005 to 2010. The overall median rainfall was $63.1 \mathrm{~mm}(\mathrm{IQR}=25.9-$ 120.5). There was no difference between the mean annual rainfall before 2007 and after 2007 ( $t=-1.34$; $\mathrm{p}=0.18)$. The mean annual maximum temperature was $31.8^{\circ} \mathrm{C}( \pm 1.7)$ and the mean minimum annual temperature was $24.8( \pm 1.1)$. Malaria transmission was seasonal in Est Mono district, with each year an increase in overall cases between September and March. The number of reported malaria cases was higher from 2008 to 2010 (Figure 2).

In time series analysis, the rainfall $(\beta$ coefficient $=1.62$; $\mathrm{p}=0.05$ ) and the number of CHWs trained ( $\beta$ coefficient $=6.7 ; \mathrm{p}=0.002$ ) were positively correlated with the number of malaria cases reported (Table 5). There was no correlation between the number of $\mathrm{CHWs}$ trained and the mortality due to malaria.

Table 2 Trends of suspected and confirmed malaria cases among specific target groups in Est Mono district from 2005 to 2010

\begin{tabular}{|c|c|c|c|c|c|c|c|}
\hline \multirow[t]{2}{*}{ Years } & \multicolumn{2}{|c|}{$\begin{array}{l}\text { Children } \\
<5 \text { year }\end{array}$} & \multicolumn{2}{|c|}{$\begin{array}{l}\text { Patients } \\
\geq 5 \text { years }\end{array}$} & \multicolumn{2}{|c|}{$\begin{array}{l}\text { Pregnant } \\
\text { Women }\end{array}$} & \multirow[t]{2}{*}{$\begin{array}{l}\text { Total } \\
\text { cases }\end{array}$} \\
\hline & $\mathbf{N}$ & $\begin{array}{c}\text { Percent } \\
(\%)\end{array}$ & $\mathbf{N}$ & $\begin{array}{l}\text { Percent } \\
(\%)\end{array}$ & $\mathbf{N}$ & $\begin{array}{l}\text { Percent } \\
(\%)\end{array}$ & \\
\hline 2005 & 4974 & 48.3 & 5079 & 49.3 & 246 & 2.4 & 10299 \\
\hline 2006 & 5571 & 43.4 & 6609 & 51.5 & 663 & 5.2 & 12843 \\
\hline 2007 & 8358 & 47.0 & 8402 & 47.3 & 1016 & 5.7 & 17776 \\
\hline 2008 & 11285 & 51.1 & 9364 & 42.4 & 1419 & 6.4 & 22068 \\
\hline 2009 & 11624 & 46.5 & 11842 & 47.4 & 1524 & 6.1 & 24990 \\
\hline 2010 & 14418 & 54.0 & 10320 & 38.7 & 1940 & 7.3 & 26678 \\
\hline Total & 56230 & 49.0 & 51616 & 45.0 & 6808 & 5.9 & 114654 \\
\hline
\end{tabular}

Table 3 Malaria cases among specific target groups in Est Mono district from 2005 to 2010

\begin{tabular}{lcccccc}
\hline $\begin{array}{l}\text { Target population } \\
\text { group }\end{array}$ & $\begin{array}{c}\text { Reported cases (Suspected } \\
\text { and confirmed) }\end{array}$ & & \multicolumn{2}{c}{$\begin{array}{c}\text { Confirmed } \\
\text { cases }\end{array}$} \\
\cline { 2 - 3 } \cline { 6 - 7 } & $\mathbf{N}$ & $\mathbf{\%}$ & & $\mathbf{N}$ & $\mathbf{\%}$ \\
\hline$<5$ years & 56,230 & 49.1 & & 23,979 & 45.6 \\
$\geq 5$ years & 51,616 & 46.0 & & 24,473 & 46.6 \\
Pregnant women & 6,808 & 5.9 & & 4,087 & 7.8 \\
Total & $\mathbf{1 1 4 , 6 5 4}$ & $\mathbf{1 0 0 . 0}$ & & $\mathbf{5 2 , 5 3 9}$ & $\mathbf{1 0 0 . 0}$ \\
\hline
\end{tabular}

\section{Discussion}

The data presented here demonstrate that reported malaria cases remain high in Togo. Indeed this study found an overall increase of malaria cases in Est Mono district of 159\% in 2010 from the 2005 level. The proportion of confirmed malaria cases also increased from $17.7 \%$ in 2005 to $85.9 \%$ in 2010 . The government targeted a reduction in morbidity and mortality due to malaria by $50 \%$ in 2012 [4]. The national health information reports show an increase of malaria incidence from 80 per 1,000 in 2005 to 160 per 1,000 population in 2010 [13]. Several explanations exist for these observations. With the implementation of the new scale-up policy, there has been increased access to affordable interventions for malaria care even to populations that live more than five kilometres from a health centre. Indeed, the cost of ACT in Togo is relatively low (USD2) for a treatment course compared to the average cost of a case treatment (USD10) before 2007 in the public health centres of the district [8]. This is supported by the increase of the total number of health care visit in Est Mono district during the study period. In Kenya, it was shown that the rate of health care use increased when free high-quality care was offered [14].

The implementation of the new policy of malaria control in Togo took into account the enhancement of health care [4]. These findings suggest that several factors had impacted on the number of malaria cases reported throughout the six years - including the

Table 4 Number of personnel trained in malaria case management in Est Mono district from 2005 to 2010

\begin{tabular}{lccc}
\hline Years & $\begin{array}{c}\text { No. of health workers } \\
\text { trained }\end{array}$ & $\begin{array}{c}\text { No. of CHW } \\
\text { trained }\end{array}$ & $\begin{array}{c}\text { No. of lab persons } \\
\text { trained }\end{array}$ \\
\hline 2005 & $\mathbf{0}$ & $\mathbf{0}$ & $\mathbf{0}$ \\
2006 & $\mathbf{0}$ & $\mathbf{0}$ & $\mathbf{0}$ \\
2007 & 50 & 220 & 3 \\
2008 & 34 & 310 & 0 \\
2009 & 34 & 310 & 2 \\
2010 & 34 & 310 & 2 \\
Total & $\mathbf{1 5 2}$ & $\mathbf{1 1 5 0}$ & $\mathbf{7}$ \\
\hline
\end{tabular}




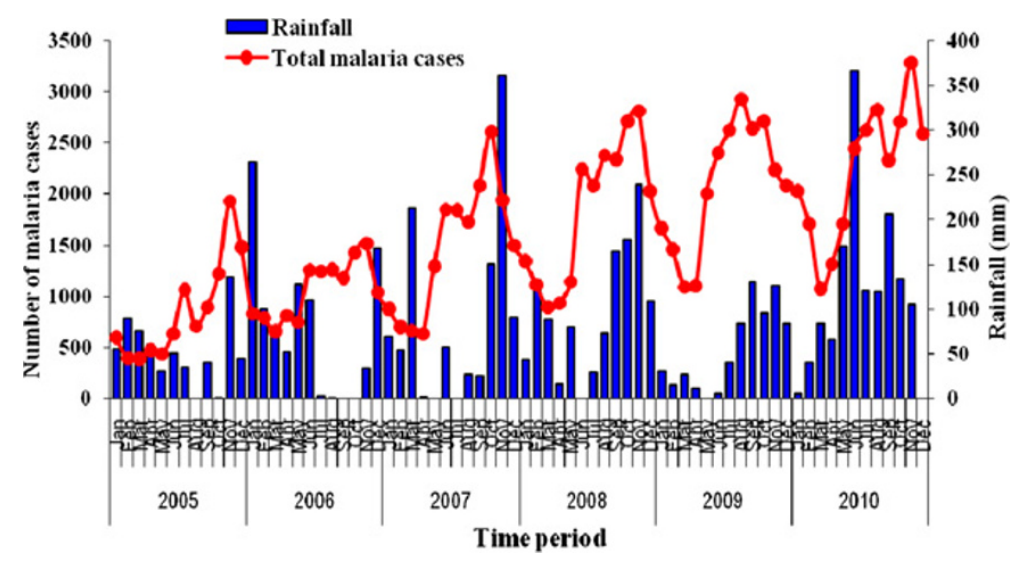

Figure 2 Relationship between monthly malaria transmission and rainfall in Est Mono district from 2005 to 2010.

training of health personnel in malaria case management; the introduction of a new treatment at lower cost; the involvement of the community through the CHWs; improvement in the monitoring and reporting system and the use of new RDTs that are simple and quick to perform and show high sensitivity. The findings are consistent with those of Nyarango et al. from an Eritrean study, where it was reported that the incidence of malaria was influenced by many factors. These factors included the access to diagnosis and treatment, risk perceptions of the net users, the training of health workers, as well as the involvement of community health agents, who increased the proportion of malaria cases treated in the community from $50 \%$ to $78 \%$ [6].

A study conducted in Uganda in five selected hospitals over a longer time period (1999 to 2009) reported a significant increase in paediatric malaria admission [15].

Table 5 Time series analysis (ARIMA): Effect of availability of ACT and number of CHWs trained on morbidity and mortality due to malaria in Est Mono district

\begin{tabular}{lccc}
\hline Variables & Coefficient & p-value & 95\% Cl \\
\hline Effect on morbidity & (number of suspected & and confirmed malaria cases) \\
Rainfall & 1.62 & 0.054 & $-0.028-3.258$ \\
Average temperature & -219.67 & 0.000 & $-318.523--120.827$ \\
Number of CHWs trained & 6.779 & 0.002 & $2.486-11.073$ \\
Use of ACT & -982.90 & 0.129 & $-2253.491-287.687$ \\
Constant & 7136.4 & 0.000 & $4371.517-9901.284$ \\
Effect on mortality (number of death attributed to malaria) \\
Rainfall & -0.0008 & 0.841 & $-0.009-0.007$ \\
Average temperature & -1.107 & 0.000 & $-1.610--0.604$ \\
Number of CHWs trained & -0.012 & 0.178 & $-0.031-0.006$ \\
Use of ACT & 2.748 & 0.305 & $-2.508-8.005$ \\
Constant & 35.955 & 0.000 & $22.259-49.651$ \\
\hline
\end{tabular}

The reasons given were the abolition of user fees in the hospitals, low intervention coverage and the high malaria transmission. In Malawi, there was no decline in annual malaria prevalence among children from 2001 to 2010 because of the disparity in treated bed coverage and the low coverage of IRS [16].

In contrast, a decline in malaria incidence has been reported in many countries $[6,9,14,17-21]$ but in most of these countries the interventions implemented included IRS and the involvement of CHWs. Similarly, in a much larger study in South Africa, where IRS was implemented and use of ACT was introduced sequentially, a reduction in the incidence of malaria was observed after implementing the use of ACT [22]. In Togo, IRS is an intervention included in the strategic plan [13] but it has not been implemented yet. ITNs remain widely used for malaria control in Togo. Nyarango et al. [6] and Sharp et al. [23] state that ITNs remain the intervention of choice for prevention of morbidity and mortality from malaria in areas of high transmission. But the preventive effect of ITNs depends on their insecticidal properties and physical integrity [24]. In a recent study conducted in Ethiopia the combination of ITNs and IRS was found to be more effective as a control measure [25].

The results of the Togo study suggest that strengthening of the malaria reporting system by the control programme could have increased the number of reported malaria cases in Est Mono. Malaria cases could have been under-reported before the introduction of the new malaria control policy, which included the enhancement of case reporting.

In this study area, there was a decrease in mortality rate from 7.2 per 10,000 in 2005 to 3.6 per 10,000 in 2010 and an increase of laboratory-confirmed cases. These findings are consistent with national data [13]. The steady decline in mortality due to malaria observed in this study has met the national target of reducing 
mortality by $50 \%$ by 2012 . The early clinical diagnosis with laboratory confirmation and appropriate treatment using $\mathrm{ACT}$ as recommended by the national guidelines are the main factors that could have contributed to the decline in mortality due to malaria in Est Mono district. It is well known that the early clinical diagnosis and laboratory confirmation are essential aspects of effective care and effective case management of malaria [6].

A study conducted in the province of KwaZulu-Natal in South Africa showed that the use of ACT decreased by $97 \%$ mortality due to malaria [22]. Similarly, in Zanzibar the decline by $52 \%$ in mortality due to malaria among children under five years old was observed after deployment of ACT [21]. The availability of ACT in Togo and personnel training in malaria case management should be reinforced.

The rainfall was correlated with the prevalence of malaria in the Togo study. The findings are consistent with findings elsewhere $[6,9,10,26]$ and confirm the role played by climatic and seasonal factors in the malaria burden. However, the pattern of rainfall did not change markedly over the six years of the study. The time series analysis shows also that the increase in reported malaria cases could be attributed to the role played by the CHWs trained in malaria case management.

\section{Limitations}

Secondary data were analysed in this study. This could have affected the data quality related to precision and the completeness during the data reporting. The study period of six years was short compared to the period used in other studies and could have affected the power of the ARIMA model. However, previous similar studies using five-year data have provided valid results [6]. Some other factors such as migration, socioeconomic conditions, level of knowledge, community attitudes to and practices of malaria control may have influenced the changes in the burden of malaria that were not taken into account. However, the results of this study are likely to be generalizable to other districts of Togo, since health service delivery and the period of malaria control interventions are similar in all districts. The trends of malaria prevalence and mortality are likely to be representative of those for the entire country.

\section{Conclusion}

This study shows an increase of reported malaria cases and a reduction in mortality due to malaria in Est Mono district with the introduction of ITNs, ACT and the involvement of CHWs. Multicentre data analysis over longer periods should be carried out in West African countries where the transmission of malaria is still high to find out the impact of malaria control strategies on the burden of the disease. The introduction of IRS and other integrated vector control management strategies in Togo needs to be considered for reducing malaria transmission in order to meet the Abuja Declaration goals, which are only three years left from deadline.

\section{Abbreviations}

ACT: Artemisinin-based combination therapy; ARIMA: Autoregressive Integrated Moving Average; CHW: Community Health Worker; RBM: Roll Back Malaria; ITN: Insecticide-treated net; IRS: Indoor residual spraying;

DDT: Dichlorodiphenyltrichloroethane; RDT: Rapid diagnostic test.

\section{Competing interests}

Authors declare that there is no conflict of interest.

\section{Authors' contributions}

DEL participated to the study design, undertook the field study, conducted the data collection, analysis and interpretation, and wrote the manuscript. PT was involved in the study design, supervised data collection and participated in data analysis. BS was involved in the data collection, analysis and interpretation and revised the manuscript. KST was involved in the study design, data analysis and interpretation and revised the manuscript. SG and PW participated in data analysis and interpretation of results, in writing and reviewing the manuscript and provided comments on the manuscript. $C$ de Jager was responsible for the conception of the study and its overall scientific management, for analysis and interpretation, and the preparation of the final manuscript. All the authors have read and approved the final manuscript to be submitted for publication.

\section{Acknowledgements}

We thank the Ministry of Health of Togo for permitting this study to be conducted and the Est Mono district management team for its cooperation in data collection. We acknowledge AFENET and SAFELTP for providing us with technical and financial support to conduct the study and write the manuscript. Many thanks to Olivia Namusi, DastanBagenda, Lazarus Kuonza, Tempia Stefano, Simon Kasasa, ElizeusRutebemberwa and Melissa Dahlke for their guidance in the drafting of this manuscript.

\section{Author details}

'Division de l'Epidémiologie, Ministère de la Santé du Togo, BP: 1396, Lomé, Togo. ${ }^{2}$ UP Centre for Sustainable Malaria Control, School of Health Systems \& Public Health, University of Pretoria, Pretoria, South Africa. ${ }^{3}$ FacultéMixte de Médecineet de Pharmacie, Université de Lomé, Lomé, Togo. ${ }^{4}$ South African Field Epidemiology and Laboratory Training Programme (SAFELTP), National Institute for Communicable Diseases, Johannesburg, South Africa. ${ }^{5}$ African Field Epidemiology Network (AFENET), Kampala, Uganda.

Received: 7 September 2012 Accepted: 21 November 2012 Published: 23 November 2012

\section{References}

1. World Health Organization: World Malaria Report. Geneva, Switzerland: WHO 2010.

2. Guinovart C, Navia MM, Tanner M, Alonso PL: Malaria: burden of disease. Curr Mol Med 2006, 6:137-140.

3. Snow R, Craig M, Deichmann U, Marsh K: Estimating mortality, morbidity and disability due to malaria among Africa's non-pregnant population. Bull World Health Organ 1999, 77:624-640.

4. Ministère de la Santé: Plan stratégique national du Togo "Faire reculer le paludisme" 2006-2010. Lomé, Togo: Programme National de Lutte contre le Paludisme; 2006.

5. Snow RW, Marsh K: Malaria in Africa: progress and prospects in the decade since the Abuja Declaration. Lancet 2010, 376:137-139.

6. Nyarango PM, Gebremeskel T, Mebrahtu G, Mufunda J, Abdulmumini U, Ogbamariam A, Kosia A, Gebremichael A, Gunawardena D, Ghebrat Y, Okbaldet Y: A steep decline of malaria morbidity and mortality trends in Eritrea between 2000 and 2004: the effect of combination of control methods. Malar J 2006, 5:33.

7. Goodman CA, Coleman PG, Mills AJ: Cost-effectiveness of malaria control in sub-Saharan Africa. Lancet 1999, 354:378-385. 
8. Ministère de la santé: Plan de développement sanitaire 2008-2012. Elavagnon, Togo: District de l'Est Mono; 2008.

9. Ngomane $L$, de Jager $C$ : Changes in malaria morbidity and mortality in Mpumalanga Province, South Africa (2001-2009): a retrospective study. Malar J 2012, 11:19.

10. Huang F, Zhou S, Zhang S, Wang H, Tang L: Temporal correlation analysis between malaria and meteorological factors in Motuo County Tibet. Malar J 2011, 10:54.

11. Monti K, Koch GG, Sawyer J: An application of segmented linear regression models to the analysis of data from a cross-sectional growth experiment, Institute of Statistics Mimeo Series vol. 1200. Chapel Hill: University of North Carolina; 1978.

12. Gillings D, Makuc D, Siegel E: Analysis of interrupted time series mortality trends: an example to evaluate regionalized perinatal care. Am J Public Health 1981, 71:38-46.

13. Ministère de la Santé: Plan stratégique 2011-2015 de lutte contre le paludisme au Togo. Lomé, Togo: Programme National de Lutte contre le Paludisme; 2011.

14. Burgert CR, Bigogo G, Adazu K, Odhiambo F, Buehler J, Breiman RF, Laserson K, Hamel MJ, Feikin DR: Impact of implementation of free highquality health care on health facility attendance by sick children in rural western Kenya. Trop Med Int Health 2011, 16:711-720.

15. Okiro EA, Bitira D, Mbabazi G, Mpimbaza A, Alegana VA, Talisuna AO, Snow RW: Increasing malaria hospital admissions in Uganda between 1999 and 2009. BMC Med 2011, 9:37.

16. Roca-Feltrer A, Kwizombe CJ, Sanjoaquin MA, Sesay SS, Faragher B, Harrison J, Geukers K, Kabuluzi S, Mathanga DP, Molyneux E, Chagomera M, Taylor T, Molyneux M, Heyderman RS: Lack of decline in childhood malaria, Malawi, 2001-2010. Emerg Infect Dis 2012, 18:272-278.

17. Mutuku FM, King CH, Mungai P, Mbogo C, Mwangangi J, Muchiri EM, Walker ED, Kitron U: Impact of insecticide-treated bed nets on malaria transmission indices on the south coast of Kenya. Malar J 2011, 10:356.

18. terKuile FO, Terlouw DJ, Phillips-Howard PA, Hawley WA, Friedman JF, Kolczak MS, Kariuki SK, Shi YP, Kwena AM, Vulule JM, Nahlen BL: Impact of permethrin-treated bed nets on malaria and all-cause morbidity in young children in an area of intense perennial malaria transmission in western Kenya: cross-sectional survey. AmJTrop Med Hyg 2003, 68:100-107.

19. Kleinschmidt I, Schwabe C, Shiva M, Segura JL, Sima V, Mabunda SJ, Coleman M: Combining indoor residual spraying and insecticide-treated net interventions. AmJTrop Med Hyg 2009, 81:519-524.

20. Gerritsen AA, Kruger P, van der Loeff MF, Grobusch MP: Malaria incidence in Limpopo Province, South Africa, 1998-2007. Malar J 2008, 7:162.

21. Bhattarai A, Ali AS, Kachur SP, Martensson A, Abbas AK, Khatib R, Al-Mafazy AW, Ramsan M, Rotllant G, Gerstenmaier JF, Molteni F, Abdulla S, Montgomery SM, Kaneko A, Björkman A: Impact of artemisinin-based combination therapy and insecticide-treated nets on malaria burden in Zanzibar. PLoS Med 2007, 4:e309.

22. Barnes KI, Durrheim DN, Little F, Jackson A, Mehta U, Allen E, Dlamini SS, Tsoka J, Bredenkamp B, Mthembu DJ, White NJ, Sharp BL: Effect of artemether-lumefantrine policy and improved vector control on malaria burden in KwaZulu-Natal South Africa. PLoS Med 2005, 2:e330.

23. Sharp B, van Wyk P, Sikasote JB, Banda P, Kleinschmidt I: Malaria control by residual insecticide spraying in Chingola and Chililabombwe, Copperbelt Province Zambia. Trop Med Int Health 2002, 7:732-736.

24. Smith SC, Joshi UB, Grabowsky M, Selanikio J, Nobiya T, Aapore T: Evaluation of bednets after 38 months of household use in northwest Ghana. AmJTrop Med Hyg 2007, 77:243-248.

25. Bekele D, Belyhun Y, Petros B, Deressa W: Assessment of the effect of insecticide-treated nets and indoor residual spraying for malaria control in three rural kebeles of Adami Tulu District South Central Ethiopia. Malar J 2012, 11:127.

26. Chaves LF, Hashizume M, Satake A, Minakawa N: Regime shifts and heterogeneous trends in malaria time series from Western Kenya Highlands. Parasitology 2012, 139:14-25.

\section{doi:10.1186/1475-2875-11-389}

Cite this article as: Landoh et al:: Morbidity and mortality due to malaria in Est Mono district, Togo, from 2005 to 2010: a times series analysis. Malaria Journal 2012 11:389. 